\title{
MATHEMATICAL MODELING OF AIR VELOCITY IN TECHNOLOGICAL MODULE FOR GROWING BROILERS USING TUNNEL VENTILATION SYSTEM
}

\author{
Ilya Plaksin ${ }^{1}$, Alexey Trifanov ${ }^{1}$, Sergei Plaksin ${ }^{2}$ \\ ${ }^{1}$ Federal Scientific Agroengineering Centre VIM, Russia; \\ ${ }^{2}$ Novosibirsk State Pedagogical University, Russia \\ nii@sznii.ru,nspu@nspu.net
}

\begin{abstract}
Small-scale poultry enterprises today are a significant part of the Russian economy. They perform important socio-demographic functions contributing to the preservation and development of rural areas. In addition, poultry farming is the only alternative to pig farming in terms of production intensity and output. However, currently, there are no technical, technological and space-planning solutions for small-scale poultry farms, which would provide a quick start-up of production, minimal labour costs and maximal use of the genetic potential of birds. In this context, a technological module for growing chicken broilers was designed and manufactured. A mathematical model was created to determinethe air velocity in the technological module by the mass, momentum and energy conservation equations. The technological module was equipped with a cage battery with three identical tiers. Each tier was supplied with an air inlet and two exhaust fans forming a tunnel ventilation system. The capacity of each fan was $900 \mathrm{~m}^{3} \cdot \mathrm{h}^{-1}$ according to the designing recommendations for poultry houses. The airflow was computer-simulated within one tier. The applied decomposition method was based on an implicit difference scheme, which had a second-order approximation in spatial variables and a firstorder approximation in time. The installed fans were found to comply with all the requirements for the parameters of the designed ventilation system. Namely, they complied with the restriction of the air velocity inside the cage battery tier not to exceed $1 \mathrm{~m} \cdot \mathrm{s}^{-1}$. In addition, the study results allowed choosing the optimal system for forced removal of exhaust air from the cage battery tier in the technological module for broiler chicken growing.
\end{abstract}

Keywords: agriculture; poultry farming; broiler chicken; technological module; mathematical model.

\section{Introduction}

Poultry farming is an agriculture branch specializing in poultry meat and eggs production. Its byproducts are the down, feather and waste products used in making meat-and-bone meal and valuable organic fertilisers. The current poultry production does not depend on the own land availability as it works mainly with the purchased complete feed.

Poultry meat occupiesthe first place in the per capita consumption of various meat types in Russia with an indicator of $45.13 \%$ or 34.7 kilograms in natural units. Its popularity is justified by the cost, taste and nutritional properties, as well as the confessional characteristics of the country.

From 2010 to 2019, there has been a steady increase in poultry meat production in Russia on all farm categories from 2847 to 5010 thousand tons, respectively [1]. Its dynamic pattern is shown in Fig. 1.

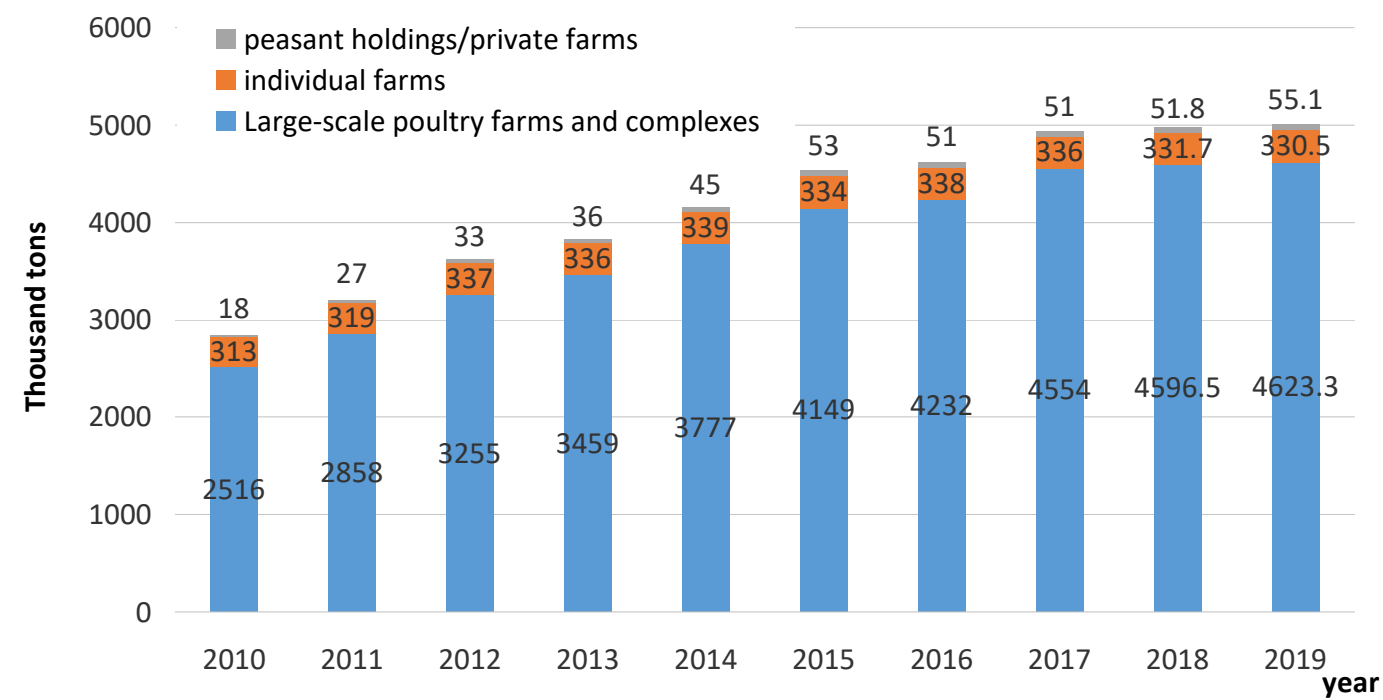

Fig. 1. Poultry meat production in Russia by farm categories (slaughter weight, thousand tons) 
This trend is still in place, but the growth rate is declining every year. From 2017 to 2018, this indicator was $0.8 \%$, and from 2018 to 2019 - only $0.6 \%$. The country's domestic market is saturated with poultry meat and the state stopped construction and reconstruction lending for large poultry enterprises. The share of small poultry farms, such as peasant holdings, and private subsidiary farms remains at the level of 7-8\%. However, in 2019 there was a $6 \%$ increase in poultry meat production in such farms compared to 2018 since some pig-rearing enterprises transferred to poultry production due to the African swine fever spread.

In poultry meat production profile, broiler meat ranks first, then comes the meat of culled laying hens, turkey meat and the meat of other poultry, such as geese, ducks, quails, guinea fowl, pigeons, etc.

The buying preferences on the retail market, the feed conversion rate below 1.7, the broiler fattening period of 42 days, and no need for the carcass cutting operation justify the large volume of broiler meat production [2-4].

Broiler meat is produced in large poultry farms and complexes as is the case with general poultry meat production. The small-scale farms have a relatively small share in this regard, as they mainly apply inefficient poultry housing technologies. Moreover, there are no state-of-the-art knowledgebased technical, technological and space-planning solutions for them to achieve the maximal use of the genetic potential of poultry, lower production costs and, consequently, competitive new products.

The small-scale agricultural enterprises, in general, and small poultry farms, in particular, have important social and demographic functions contributing to the country's rural areas sustainability. Therefore, the solutions need to be developed that would meet all current requirements to farm management.

Based on the tasks outlined, the Federal Scientific Agroengineering Centre VIM (branch IEEP in Saint Petersburg) designed and manufactured a prototype of a technological module for broiler fattening. It is a container-type mobile unit with the dimensions of $6 \times 2.5 \times 3.2$ meters. It is equipped with the multi-tier cage battery with hopper feeders, nipple drinkers, infrared heaters, fan exhausters and fresh air windows on each tier. The trays under each tier collect the poultry manure. LED lamps provide lighting [5]. Fig. 2 shows the general view of the technological module for broiler fattening and its main components.

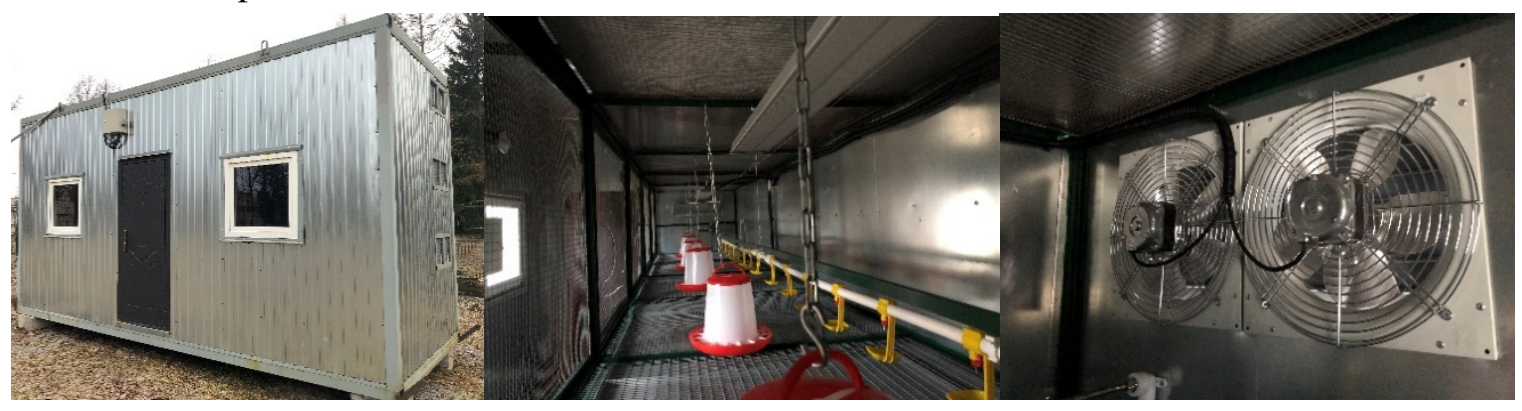

Fig. 2. Technological module for broiler fattening

The main problem is to organize such ventilation, which would provide the required air exchange inside the room and the optimal inside air flow rate not to exceed the recommended $1 \mathrm{~m} \cdot \mathrm{s}^{-1}$.

The presented technological module may house up to 310 fattening broilers at a time taking into account the required air exchange, which is $0.7-1.0 \mathrm{~m}^{3} \cdot \mathrm{h}^{-1}$ per kilogram of live weight in the cold season and $7 \mathrm{~m}^{3} \cdot \mathrm{h}^{-1}$ per kilogram of live weight in the warm season. Therefore, the needed ventilation system has to provide the air exchange in the range from 775 to $5425 \mathrm{~m}^{3} \cdot \mathrm{h}^{-1}$ [6;7]. As the technological module has a small internal volume of $40.02 \mathrm{~m}^{3}$, it is necessary to model the ventilation system parameters before the module is assembled and the equipment is installed for timely adjustment of its design.

The air velocity in a tunnel ventilation system is currently simulated for the poultry farm facilities of large production capacity [8-10]. However, the created models are not applicable to the designed technological module due to its small overall dimensions and the use of the cage housing system of broilers. 
Consequently, the study objective was to create a mathematical model for determining the air velocity in such technological module, using the tunnel ventilation system and to substantiate the choice and location of the exhaust fans.

\section{Materials and methods}

The mathematical modeling method, which described axially symmetric variable airflow in the technological module for broiler fattening, was applied to calculate the parameters of the forced ventilation system to be installed. The variable airflow inside the poultry house was considered in the ideal polytropic gas model and was described by mass, momentum and energy conservation equations.

The airflow was computer-simulated within one tier. Fig. 3 shows the layout of the ventilation equipment in place.

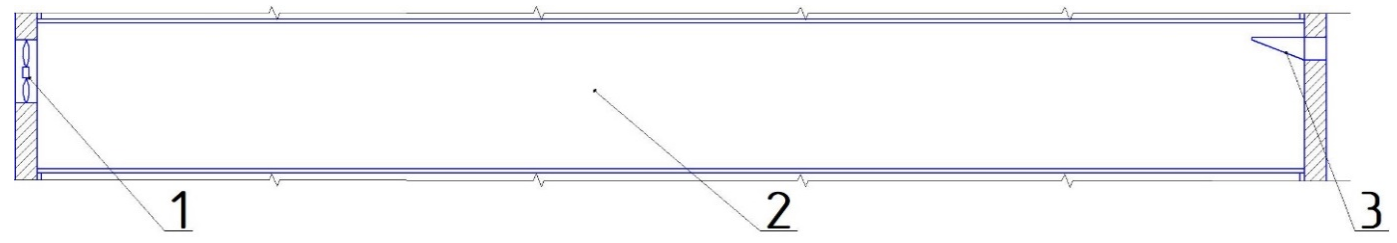

Fig. 3. Layout of the ventilation equipment in a cage battery tire in the broiler chicken fattening module: 1 - exhaust fan; 2 - cage battery tier; 3 - air inlet window

The decomposition method was used in computer modelling based on an implicit difference scheme having a second-order approximation in spatial variables and a first-order approximation in time.

In the study, the resulting model was tested using MS Excel and ABC Pascal tools.

Under the normal conditions, the most gases satisfy the ideal gas law (gas equation) [11]:

$$
p=R_{g} \rho T,
$$

where $R_{g}$ - gasconstant, as related to the molecular weight of the gas;

$p$ - gas pressure;

$\rho$ - gas density;

$T$ - absolute gas temperature.

The air was considered in the ideal gas model with the constant specific heat capacities as polytropic gas.

Specific (per unit of mass) internal energy $e$ of a polytropic gas is a linear function of only one variable $T$, i.e. $e=c_{V} T$ ( $c_{V}=$ const, $c_{V}$ - specific gas heat capacity under constant volume) [11]. The following expression describes the internal energy of the polytropic gas from equation (1):

$$
e=\frac{1}{\gamma-1} \frac{p}{\rho}
$$

where $\quad \gamma=1+\frac{R_{g}}{c_{V}}-$ polytropic exponent.

For diatomicpolytropicgas, $\gamma=1.4$ that is a good approximation for air [11].

The polytropic gas model gained widespread use in the applied research owing to its comparative analytical simplicity and a good approximation to the truth, validated by experience [12].

Airflow in Cartesian coordinates $\left(x_{1}, x_{2}, x_{3}\right)$ is described by the equations of mass, momentum and energy conservation [11]:

$$
\begin{gathered}
\frac{\partial \rho}{\partial t}+\frac{\partial}{\partial x_{j}}\left(\rho v_{j}\right)=0 \\
\frac{\partial\left(\rho v_{i}\right)}{\partial t}+\frac{\partial}{\partial x_{j}}\left(\rho v_{i} v_{j}\right)+\frac{\partial p}{\partial x_{i}}=0(i=1,2,3),
\end{gathered}
$$




$$
\frac{\partial}{\partial t}\left(\frac{1}{2} \rho q^{2}+\rho e\right)+\frac{\partial}{\partial x_{j}}\left\{\left(\frac{1}{2} \rho q^{2}+\rho e+p\right) v_{j}\right\}=0
$$

where $q=|v|$ velocity vector module, $v=\left(v_{1}, v_{2}, v_{3}\right)$;

$$
t \text { - time. }
$$

In these equations, as in the equations below, the summation from 1 to 3 over the repeated indices is performed.

In our model, equations (3)-(5) form a complete system of equations for five air flow quantities $\rho$, $p, v_{i}$. In this case, the internal gas energy is expressed in terms of pressure and density using the expression (2).

According to [11; 12], it follows from equations (3)-(5) and the fundamental property of heat and mechanical energy equivalence in the form of the first law of thermodynamics that the entropy remains constant along the particle trajectory. In general case, the entropy can take on different values on the trajectories of various particles. But, if the gas was initially at rest with the uniform entropy $S_{0}$, then for a continuous flow without shock waves or any other discontinuities $S=S_{0}$ on the trajectory of each particle. Consequently, entropy remains constant over the entire gas flow region. In this case, pressure is a function of density only. According to equations (2)-(5), for polytropic gas this function takes the form:

$$
p=p_{0}\left(\frac{\rho}{\rho_{0}}\right)^{\gamma}
$$

where $p_{0}, \rho_{0}$ - initial unperturbed values of gas pressure and density. (6).

This way, the continuous air flow will be considered in the model set by equations (3), (4), and

\section{Resultsanddiscussion}

Let us consider the model of the cage battery tier in the technological module in the form of a right circular cylinder. Fig. 4 shows its axial section. The axis $O Z$ coincides with the cylinder axis $O E$; $O B$ and $E C$ are the radii of its bases $(O B=E C=R), B C$ is its generator $(B C=L)$.

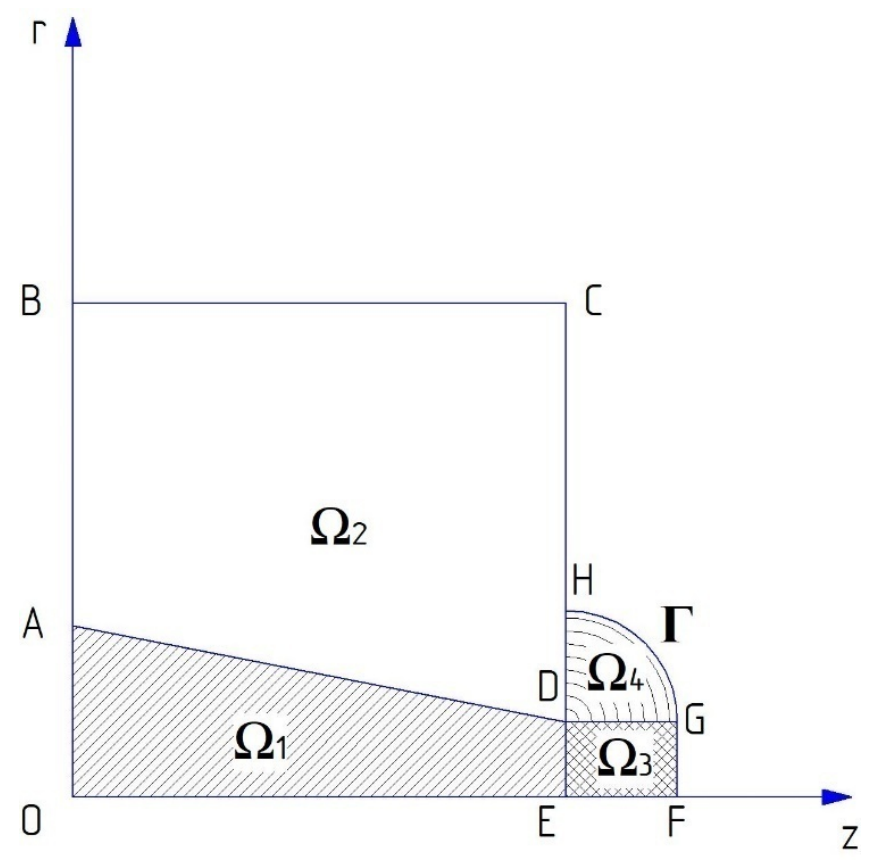

Fig. 4. Axial section of the cage battery tier in the technological module

The air is forced from the tier by a fan through a circular hole with point $O$ as the centre and the radius $R_{0}$ shown in Fig. 4 as the dashed segment $O A$. The air enters the tier from an unperturbed 
homogeneous stationary external environment through a circular hole with point $E$ as the centre and the radius $r_{0}$ shown in Fig. 4 as the dashed segment $E D$.

Forced air movement within this model is axisymmetric.

Let us introduce the following non-dimensional variables:

$$
\begin{gathered}
t=t^{\prime} \cdot t_{0} z=z^{\prime} \cdot L r=r^{\prime} \cdot L R=R^{\prime} \cdot L R_{0}=R_{0}^{\prime} \cdot L r_{0}=r_{0}^{\prime} \cdot L \rho=\rho^{\prime} \cdot \rho_{0} u=u^{\prime} \cdot \frac{L}{t_{0}}, \\
\bar{v}=\bar{v}^{\prime} \cdot \frac{L}{t_{0}} c_{0}=c_{0} \cdot \frac{L}{t_{0}} p_{0}=p_{0}^{\prime} \cdot \rho_{0} \cdot\left(\frac{L}{t_{0}}\right)^{2} p=p^{\prime} \cdot \rho_{0} \cdot\left(\frac{L}{t_{0}}\right)^{2},
\end{gathered}
$$

where $z, r$-cylindrical axial (coordinates);

$u, \bar{v}-$ velocity vector projections on $O Z$ axis and on the axis perpendicular plane;

$c_{0}^{2}=\frac{\gamma p_{0}}{\rho_{0}}-$ squared adiabatic sound velocity in non-turbulent air at rest $p=p_{0}, \rho=\rho_{0}$,

$u_{0}=0, \bar{v}_{0}=0$

$c_{0}{ }^{2}=\gamma p_{0}{ }^{\prime}$

$t_{0}$ - characteristic time required for the fan to reach the steady-state operating mode.

The system of equations (3), (4), (6) is hyperbolic. For an axisymmetric air movement in nondimensional cylindrical coordinates, it takes the form (from this point on, the bars are omitted) [13]:

$$
\begin{gathered}
\frac{\partial c^{2}}{\partial t}+u \frac{\partial c^{2}}{\partial z}+\bar{v} \frac{\partial c^{2}}{\partial r}+(\gamma-1) c^{2}\left(\frac{\partial u}{\partial z}+\frac{\partial \bar{v}}{\partial r}\right)+\frac{(\gamma-1) c^{2} \bar{v}}{r}=0, \\
\frac{\partial u}{\partial t}+u \frac{\partial u}{\partial z}+\bar{v} \frac{\partial u}{\partial r}+\frac{1}{\gamma-1} \frac{\partial c^{2}}{\partial z}=0, \\
\frac{\partial \bar{v}}{\partial t}+u \frac{\partial \bar{v}}{\partial z}+\bar{v} \frac{\partial \bar{v}}{\partial r}+\frac{1}{\gamma-1} \frac{\partial c^{2}}{\partial r}=0, \\
c^{2}=c_{0}^{2} \rho^{\gamma-1},
\end{gathered}
$$

where $\quad c^{2}=\frac{\gamma p}{\rho}-$ squared adiabatic sound velocity.

Fig.4 in the plane $(z, r)$ shows the air flow domain at a fixed time point $t, t>t_{*}$, where $t_{*}=1 / c_{0}$ the moment the rarefaction wave front reaches point $E$. The air flow domain boundaries are the rarefaction wave front $\Gamma$, the symmetry axis and the surface of the tire. The rarefaction wave front expanding in the unperturbed air at rest with the speed $c_{0}$ consists of a straight line segment $G F$ :

$$
z=1+c_{0} \cdot\left(t-t_{*}\right), 0 \leq r \leq r_{0}
$$

and a quarter circle defined by

$$
(z-1)^{2}+\left(r-r_{0}\right)^{2}=c_{0}^{2}\left(t-t_{*}\right)^{2}
$$

The forced air removal velocity near the hole $O A\left(z=0,0 \leq r \leq R_{0}\right)$ may be presented as

$$
u(0, r, t)=\frac{a_{m}(t)}{2}\left(\cos \left(\frac{\pi r}{R_{0}}\right)+1\right)
$$

where

$$
a_{m}(t)=\left\{\begin{array}{c}
a_{m 0} t^{\frac{1}{k}}, \text { under } 0 \leq t \leq 1 \\
a_{m 0}, \text { under } t>1
\end{array}\right.
$$

where $a_{m 0}-$ non-dimensional velocity amplitude;

$k$-determined by the fan specifications. 
So the problem of air movement by forced ventilation is reduced to solving a hyperbolic system of equations (7)-(10) in the above domain under the following boundary and initial conditions:

- $\Gamma: u=v=0, p=p_{0}, \rho=1$;

- $O A$ : $u=u(0, r, t)$ (velocity value specified by expression (13)) for $0 \leq r \leq R_{0}$;

- $A B: u(0, r, t)=0$, for $R_{0} \leq r \leq R$;

- $B C: \bar{v}(z, R, t)=0$;

- $C D: u(1, r, t)=0$, for $r_{0} \leq r \leq R$;

- $D H: u(1, r, t)=0$, for $r_{0} \leq r \leq r_{0}+c_{0} \cdot\left(t-t_{*}\right)$;

- $O F: \bar{v}(z, 0, t)=0$ for $0 \leq z \leq 1+c_{0} \cdot\left(t-t_{*}\right)$, (symmetry condition);

- $t=0: u=v=0, p=p_{0}, \rho=1$.

Forcomputer-assisted problem solving we divide the air flow domaininto:

- two domains $\Omega_{i}, i=1,2$ (Fig.4) for, $0 \leq t \leq t_{*}$;

- four domains $\Omega_{i}, i=1,2,3,4$ (Fig.4) for $t>t_{*}$.

The dashed line segment $A D$ (Fig. 4) is determined by the straight-line equation

$$
r=\left(r_{0}-R_{0}\right) z+R_{0}, z \in[0 ; 1]
$$

We map each domain $\Omega_{i}, i=1,2$ on the rectangular domain $\Omega_{i}{ }^{\prime}, i=1,2$ with the following change of variables (transposition):

$$
\begin{gathered}
\left\{\begin{array}{c}
\xi_{1}=z \\
\eta_{1}=\frac{r}{\left(r_{0}-R_{0}\right) z+R_{0}}, \quad\left(\xi_{1}, \eta_{1}\right) \Omega_{1}^{\prime}, \Omega_{1}^{\prime}=[0 ; 1] \times[0 ; 1]
\end{array}\right. \\
\left\{\begin{array}{c}
\xi_{2}=z \\
\eta_{2}=\frac{r-\left(\left(r_{0}-R_{0}\right) z+R_{0}\right)}{R-\left(\left(r_{0}-R_{0}\right) z+R_{0}\right)}+1
\end{array},\left(\xi_{2}, \eta_{2}\right) \Omega_{2}^{\prime}, \Omega_{2}^{\prime}=[0 ; 1] \times[1 ; 2],\right.
\end{gathered}
$$

Here, points $\left(\xi_{1}, 1\right) \in \Omega_{1}{ }^{\prime},\left(\xi_{2}, 1\right) \in \Omega_{2}{ }^{\prime}$ under $\xi_{1}=\xi_{2}$ correspondtoone and the same point of the $A D$ segment.

The system of equations (7)-(9) in the domain $\Omega_{i}{ }^{\prime}, i=1,2$ takes the form:

$$
\begin{gathered}
\frac{\partial c^{2}}{\partial t}+u \frac{\partial c^{2}}{\partial \xi_{i}}+\left(A_{i} \bar{v}-B_{i} u\right) \frac{\partial c^{2}}{\partial \eta_{i}}+(\gamma-1) c^{2}\left(\frac{\partial u}{\partial \xi_{i}}-B_{i} \frac{\partial u}{\partial \eta_{i}}+A_{i} \frac{\partial \bar{v}}{\partial \eta_{i}}\right)+(\gamma-1) c^{2} \bar{v} D_{i}=0 \\
\frac{\partial u}{\partial t}+u \frac{\partial u}{\partial \xi_{i}}+\left(A_{i} \bar{v}-B_{i} u\right) \frac{\partial u}{\partial \eta_{i}}+\frac{1}{\gamma-1}\left(\frac{\partial c^{2}}{\partial \xi_{i}}-B_{i} \frac{\partial c^{2}}{\partial \eta_{i}}=0,\right) \\
\frac{\partial \bar{v}}{\partial t}+u \frac{\partial \bar{v}}{\partial \xi_{i}}+\left(A_{i} \bar{v}-B_{i} u\right) \frac{\partial \bar{v}}{\partial \eta_{i}}+\frac{1}{\gamma-1} A_{i} \frac{\partial c^{2}}{\partial \eta_{i}}=0
\end{gathered}
$$

where $A_{i}, B_{i}, D_{i}-$ variable coefficients, with the values being:

$$
\begin{gathered}
A_{1}=\frac{1}{\left(r_{0}-R_{0}\right) \xi_{1}+R_{0}} ; B_{1}=\frac{\left(r_{0}-R_{0}\right) \eta_{1}}{\left(r_{0}-R_{0}\right) \xi_{1}+R_{0}} ; A_{2}=\frac{1}{R-\left(\left(r_{0}-R_{0}\right) \xi_{2}+R_{0}\right)} ; B_{2}=\frac{\left(r_{0}-R_{0}\right)\left(2-\eta_{2}\right)}{R-\left(\left(r_{0}-R_{0}\right) \xi_{2}+R_{0}\right)} ; \\
D_{1}=\frac{A_{1}}{\eta_{1}} ; D_{2}=\frac{A_{2}}{\left(\left(\eta_{2}-2\right)+A_{2} R\right)} .
\end{gathered}
$$

In the domain $\Omega_{4}$, we introduce the polar coordinate system $(\mu, \varphi)$ centered at point 
$D: z-1=\mu \cos \varphi, r-r_{0}=\mu \sin \varphi$. In polar coordinates, the rarefaction wave front (16) in this domain is the coordinate line: $\mu=c_{0}\left(t-t_{*}\right), 0 \leq \varphi \leq \pi / 2$. In the domain $\Omega_{4}=\left[0, c_{0}\left(t-t_{*}\right)\right] \times[0, \pi / 2]$ the system of equations (7)-(9) takes the form:

$$
\begin{gathered}
\frac{\partial c^{2}}{\partial t}+\bar{v}_{\mu} \frac{\partial c^{2}}{\partial \mu}+\frac{\bar{v}_{\varphi}}{\mu} \frac{\partial c^{2}}{\partial \varphi}+(\gamma-1) c^{2}\left(\frac{\partial \bar{v}_{\mu}}{\partial \mu}+\frac{1}{\mu} \frac{\partial \bar{v}_{\varphi}}{\partial \varphi}+\frac{\bar{v}_{\mu}}{\mu}\right)+\frac{(\gamma-1) c^{2}\left(\bar{v}_{\mu} \sin \varphi+\bar{v}_{\varphi} \cos \varphi\right)}{r_{0}+\mu \sin \varphi}=0, \\
\frac{\partial \bar{v}_{\mu}}{\partial t}+\bar{v}_{\mu} \frac{\partial \bar{v}_{\mu}}{\partial \mu}+\frac{\bar{v}_{\varphi}}{\mu} \frac{\partial \bar{v}_{\mu}}{\partial \varphi}-\frac{\bar{v}_{\varphi}^{2}}{\mu}+\frac{1}{\gamma-1} \frac{\partial c^{2}}{\partial \mu}=0, \\
\frac{\partial \bar{v}_{\varphi}}{\partial t}+v_{\mu} \frac{\partial \bar{v}_{\varphi}}{\partial \mu}+\frac{\bar{v}_{\varphi}}{\mu} \frac{\partial \bar{v}_{\varphi}}{\partial \varphi}+\frac{\bar{v}_{\varphi} \bar{v}_{\mu}}{\mu}+\frac{1}{(\gamma-1) \mu} \frac{\partial c^{2}}{\partial \varphi}=0,
\end{gathered}
$$

where $\bar{v}_{\mu}, \bar{v}_{\varphi}-$ radial and circumferential components of the velocity vector,

$$
\begin{aligned}
& \bar{v}_{\mu}=u \cos \varphi+\bar{v} \sin \varphi ; \\
& \bar{v}_{\varphi}=\bar{v} \cos \varphi-u \sin \varphi .
\end{aligned}
$$

Moreover,

$$
u=\bar{v}_{\mu} \cos \varphi-\bar{v}_{\varphi} \sin \varphi, \bar{v}=\bar{v}_{\mu} \cos \varphi+\bar{v}_{\varphi} \sin \varphi \text { and } q^{2}=u^{2}+v^{2}=\bar{v}_{\mu}^{2}+\bar{v}_{\varphi}^{2} .
$$

For the computer-assisted calculation in the domains $\Omega_{i}, i=3,4$ it is convenient to proceed to the domains $\Omega_{i}{ }^{\prime}, i=3,4$ with fixed boundaries with the following change of variables (transposition):

$$
\left\{\begin{array}{c}
\xi_{3}=\frac{z-1}{c_{0}(t-t)}+1 \\
\eta_{3}=\frac{r}{r_{0}}
\end{array},\left(\xi_{3}, \eta_{3}\right) \Omega_{3}^{\prime}, \Omega_{3}^{\prime}=[1 ; 2] \times[0 ; 1],\right.
$$

here, points $\left(1, \eta_{1}\right) \in \Omega_{1}{ }^{\prime},\left(1, \eta_{3}\right) \in \Omega_{3}{ }^{\prime}$ under $\eta_{1}=\eta_{3}$ correspond to one and the same point of the ED segment;

$$
y=\frac{\mu}{c_{0}\left(t-t_{*}\right)},(y, \varphi) \Omega_{4}{ }^{\prime}, \Omega_{4}{ }^{\prime}=[0 ; 1] \times\left[0 ; \frac{\pi}{2}\right],
$$

here, points $\left(1, \xi_{3}\right) \in \Omega_{3}{ }^{\prime},\left(1, \xi_{4}\right) \in \Omega_{4}{ }^{\prime}$ under $\xi_{3}=y+1$ correspond to one and the same point of the $D G$ segment.

The system of equations (7)-(9) in the domain $\Omega_{3}{ }^{\prime}$ takes the form:

$$
\begin{gathered}
\frac{\partial c^{2}}{\partial t}+\left(\frac{u-c_{0}\left(\xi_{3}-1\right)}{g}\right) \frac{\partial c^{2}}{\partial \xi_{3}}+\frac{\bar{v}}{r_{0}} \frac{\partial c^{2}}{\partial \eta_{3}}+(\gamma-1) c^{2}\left(\frac{1}{g} \frac{\partial u}{\partial \xi_{3}}+\frac{1}{r_{0}} \frac{\partial \bar{v}}{\partial \eta_{3}}\right)+\frac{(\gamma-1) c^{2} \bar{v}}{r_{0} \eta_{3}}=0 \\
\frac{\partial u}{\partial t}+\left(\frac{u-c_{0}\left(\xi_{3}-1\right)}{g}\right) \frac{\partial u}{\partial \xi_{3}}+\frac{\bar{v}}{r_{0}} \frac{\partial u}{\partial \eta_{3}}+\frac{1}{(\gamma-1) g} \frac{\partial c^{2}}{\partial \xi_{3}}=0 \\
\frac{\partial \bar{v}}{\partial t}+\left(\frac{u-c_{0}\left(\xi_{3}-1\right)}{g}\right) \frac{\partial \bar{v}}{\partial \xi_{3}}+\frac{\bar{v}}{r_{0}} \frac{\partial \bar{v}}{\partial \eta_{3}}+\frac{1}{(\gamma-1) r_{0}} \frac{\partial c^{2}}{\partial \eta_{3}}=0
\end{gathered}
$$

where $g=c_{0}\left(t-t_{*}\right)$.

The system of equations (17)-(19) in the domain $\Omega_{4}{ }^{\prime}$ takes the form:

$$
\begin{gathered}
\frac{\partial c^{2}}{\partial t}+\left(\frac{\bar{v}_{\mu}-c_{0} y}{g}\right) \frac{\partial c^{2}}{\partial y}+\frac{\bar{v}_{\varphi}}{g y} \frac{\partial c^{2}}{\partial \varphi}+\frac{(\gamma-1) c^{2}}{g}\left(\frac{\partial \bar{v}_{\mu}}{\partial y}+\frac{1}{y} \frac{\partial \bar{v}_{\varphi}}{\partial \varphi}+\frac{\bar{v}_{\mu}}{y}\right)+\frac{(\gamma-1) c^{2}\left(\bar{v}_{\mu} \sin \varphi+\bar{v}_{\varphi} \cos \varphi\right)}{r_{0}+g y \sin \varphi}=0 \\
\frac{\partial \bar{v}_{\mu}}{\partial t}+\left(\frac{\bar{v}_{\mu}-c_{0} y}{g}\right) \frac{\partial \bar{v}_{\mu}}{\partial y}+\frac{\bar{v}_{\varphi}}{g y} \frac{\partial \bar{v}_{\mu}}{\partial \varphi}-\frac{\bar{v}_{\varphi}^{2}}{g y}+\frac{1}{(\gamma-1) g} \frac{\partial c^{2}}{\partial y}=0
\end{gathered}
$$




$$
\frac{\partial \bar{v}_{\varphi}}{\partial t}+\left(\frac{\bar{v}_{\mu}-c_{0} y}{g}\right)_{\mu} \frac{\partial \bar{v}_{\varphi}}{\partial y}+\frac{\bar{v}_{\varphi}}{g y} \frac{\partial \bar{v}_{\varphi}}{\partial \varphi}+\frac{\bar{v}_{\varphi} \bar{v}_{\mu}}{g y}+\frac{1}{(\gamma-1) g y} \frac{\partial c^{2}}{\partial \varphi}=0
$$

The boundary and initial conditions in the new variables take the form:

$\xi_{1}=0,0 \leq \eta_{1} \leq 1: u=u\left(0, \eta_{1}, t\right)$ (the velocity value is determined by (13), where $\left.r / R_{0}=\eta_{1}\right)$;

$$
\begin{gathered}
0 \leq \xi_{1} \leq 1, \eta_{1}=0: \bar{v}=0 ; \\
\xi_{2}=0,1 \leq \eta_{2} \leq 2: u=0 ; \\
0 \leq \xi_{2} \leq 1, \eta_{2}=2: \bar{v}=0 ; \\
\xi_{2}=1,1 \leq \eta_{2} \leq 2: u=0 ; \\
1 \leq \xi_{3} \leq 2, \eta_{3}=0: \bar{v}=0 ; \\
\xi_{3}=2,0 \leq \eta_{3} \leq 1: u=0, v=0, c^{2}=c_{0}{ }^{2} ; \\
0 \leq y \leq 1, \varphi=\frac{\pi}{2}: \bar{v}_{\varphi}=0 ; \\
y=1,0 \leq \varphi \leq \frac{\pi}{2}: \bar{v}_{\mu}=0, v_{\varphi}=0, c^{2}=c_{0}{ }^{2} ; \\
t=0: u=0, \bar{v}=0, \bar{v}_{\mu}=0, \bar{v}_{\varphi}=0, c^{2}=c_{0}{ }^{2} .
\end{gathered}
$$

On common borders of the domains under consideration, it is necessary to fulfill the continuity conditions for the corresponding functions.For the velocity at the boundary $D G$, in particular, they have the form: $u\left(\xi_{3}, 1\right)=\bar{v}_{\mu}(y, 0), \bar{v}\left(\xi_{3}, 1\right)=\bar{v}_{\varphi}(y, 0)$ under $\xi_{3}=y+1$.

The boundary value problem (14) - (16), (20) - (26) was solved numerically. The fractional step method [14] was applied, based on an implicit difference scheme with a second-order approximation in spatial variables and a first-order approximation in time. The number of grid nodes in the $\xi_{i}$ and $y$ directions was 100 , and in the $\eta_{i}$ and $\varphi$ directions it was 50 in each of the domains $\Omega_{i}{ }_{i}$. The air pressure in the axial section of the tier was determined from (6) and (10).

The following values of parameters were used in the computer solution:

$$
\begin{aligned}
L & =5.8 \mathrm{~m}, R_{0}=0.15 \mathrm{~m}, r_{0}=0.005 \mathrm{~m}, R=0.35 \mathrm{~m}, \\
a_{m 0} & =0.5 \mathrm{~m} \cdot \mathrm{s}^{-1}, t_{0}=2 \mathrm{~s}, c_{0}=340 \mathrm{~m} \cdot \mathrm{s}^{-1}, p_{0}=105 \mathrm{~h} \cdot \mathrm{m}^{-2}
\end{aligned}
$$

The process inside the cage battery tier is wave-like due to the interaction of the unloading waves reflected from the tier walls. Briefly, the process runs as follows.

Over time, as an increasing air mass is forced to move and the fan reaches the steady-state operating mode, the wave flow stabilizes. By the time moment (approximately equal to $100 t_{0}$, for the accepted values of the parameters), a perturbed air flow, which is stratified by a precursor formed by the front of the rarefaction wave and propagating through the unperturbed medium with the speed of sound, and the main perturbation are formed. Between them is a relaxation zone with perturbations decaying in time.

The spatial distribution of the air velocity modulus is non-linear, with the maximum value of the velocity modulus found in the centre of the tier. Moreover, the value of the air velocity modulus in the entire volume of the tier did not exceed $1 \mathrm{~m} \cdot \mathrm{s}^{-1}$

\section{Conclusions}

In the study, a mathematical model was developed to determine the air velocity in the technological module for broiler fattening using the tunnel ventilation system. The value of the air velocity modulus calculated by the created model did not exceed the established norm of $1 \mathrm{~m} \cdot \mathrm{s}^{-1}$ It was also concluded that the installed tunnel-type forced ventilation system provided the required air 
exchange in the technological module at any time during the fattening cycle. In addition, the power of the used fans, $900 \mathrm{~m}^{3} \cdot \mathrm{h}^{-1}$ each, was sufficient for any period of the year and the age of broilers.

Further research will aim at improving the created mathematical model, taking into account the heat from heaters and broilers.

\section{References}

[1] Экспертно-аналитический центр АПК «АБ-Центр»: Российский рынок мяса 2019. Тенденции и прогнозы (The expert and analytical centre of agro-industrial complex "ABCentre": Russian meat market 2019. Trends and forecasts). [online] [17.02.2020]. Available at: https://ab-centre.ru/news/rossiyskiy-rynok-myasa-2019-tendencii-i-prognozy (In Russian).

[2] Tolon B., YalcinS. Bone characteristics and body weight of broilers in different husbandry systems. British Poultry Science.Vol.38, Issue 1,1997, pp. 132-135.

[3] Aslam Athar M., Pervez E., Nawaz Asghar M., Ali Mian A., Zoyfro V. Effect of cage and floor rearing and their mutual transfer on the performance of broiler chicken. Pakistan Journal of Agricultural Research. Vol.11, 1990, No.3, pp. 192-196.

[4] Trifanov A.V., Plaksin I.E., Plaksin S.I. Study results of the air velocity inside the technological module for broiler chickens fattening. Engineering for Rural Development Proceedings. 2019. pp. 355-361.

[5] Плаксин И.Е., ТрифановА.В. Обоснование технико-экономических показателей технологического модуля для откорма цыплят-бройлеров (Justification of technical and economic parameters of technological module for broiler fattening). Technologies, machines and equipment for mechanised crop and livestock production: Технологии и технические средства механизации производства продукции растениеводства и животноводства. 2018. No. 95. pp. 181-188. (In Russian).

[6] Puron D., Santamaria R., Segura J. C., Alamilla J. L. Broiler performance at different stocking densities. Journal of Applied Poultry Research. Vol. 4, Issue 1, March 1995, pp. 55-60

[7] РД-АПК 1.10.05.04-13 "Методические рекомендации по технологическому проектированию птицеводческих предприятий" (Management Directive for Agro-Industrial Complex 1.10.05.04-13. Recommended Practice for Engineering Designing of Poultry Farms). Moscow: Rosinformagrotekh: M. Росинформагротех. 2013. 217 p. (In Russian).

[8] Bustamante E., García-Diego F.-J., Calvet S., Torres A., Hospitaler A. Measurement and numerical simulation of air velocity in a tunnel-ventilated broiler house. Sustainability. 2015,No. 7 (2), pp. 2066-2085.

[9] Zajicek M., Kic P. Improvement of the broiler house ventilation using the CFD simulation. Biosystems Engineering. Special Issue 1, 2012, pp. 235-242.

[10] Norton T., Sun D., Grant J., Fallon R., Dodd V. Applications of computational fluid dynamics (CFD) in the modeling and design of ventilation systems in the agricultural industry. A review. Bioresour. Technol. 2007,No. 98, pp. 2386-2414.

[11] Whitham G.B. Linear and nonlinear waves, A Wiley-Interscience Publication. John Wiley \& Sons, 1974, New York - London - Sydney - Toronto, 636 p.

[12] Овсянников Л.В. Лекции по основам газовой динамики (Lectures on the basics of gas dynamics. Moscow: Nauka.-M.: Наука, 1981. 368 p. (In Russian).

[13]Баутин С. П., Обухов А. Г. Полная система уравнений Навье-Стокса в цилиндрической системе координат (The complete system of Navier-Stokes equations in a cylindrical coordinate system) [online] [17.02.2020]. Available at: http://elib.tyuiu.ru/wp-content/uploads/2016/07/20168.pdf

[14] Яненко Н.Н. Метод дробных шагов решения многомерных задач математической физики (Fractional step method for solving the multidimensional problems of mathematical physics. Novosibirsk: Nauka).-Новосибирск, Наука, 1967, 195 p. (In Russian). 